\title{
Erratum to: Environmental modeling of uranium interstitial compositions of non-stoichiometric oxides: experimental and theoretical analysis
}

\author{
Bojidarka Ivanova
}

Published online: 2 May 2016

(C) Springer Science+Business Media Dordrecht 2016

\section{Erratum to: Environ Geochem Health DOI 10.1007/s10653-015-9752-6}

According to Dr. Michael Spiteller, he is not a coauthor of this paper. On his request, his authorship is withdrawn via this erratum. He had no contribution to the data analysis and writing process of this paper. The authorship of this paper is attributed only to Dr. Bojidarka Ivanova.

The online version of the original article can be found under doi:10.1007/s10653-015-9752-6.

B. Ivanova ( $₫)$

Lehrstuhl für Analytische Chemie, Institut für Umweltforschung, Fakultät für Chemie, Universität Dortmund, Otto-Hahn-Straße 6, 44227 Dortmund, Nordrhein-Westfalen, Germany e-mail: B.Ivanova@web.de;

B.Ivanova@infu.uni-dortmund.de 